\title{
A new airborne tandem platform for collocated measurements of microphysical cloud and radiation properties
}

\author{
W. Frey ${ }^{1}$, H. Eichler ${ }^{1}$, M. de Reus ${ }^{1}$, R. Maser ${ }^{2}$, M. Wendisch ${ }^{1}$, and S. Borrmann ${ }^{1,3}$ \\ ${ }^{1}$ Johannes Gutenberg University Mainz, Institute for Atmospheric Physics, Mainz, Germany \\ ${ }^{2}$ Enviscope GmbH, Frankfurt, Germany \\ ${ }^{3}$ Max-Planck-Institute for Chemistry, Particle Chemistry Department, Mainz, Germany \\ Received: 17 December 2008 - Published in Atmos. Meas. Tech. Discuss.: 8 January 2009 \\ Revised: 2 April 2009 - Accepted: 16 April 2009 - Published: 6 May 2009
}

\begin{abstract}
A new airborne tandem measurement platform for cloud-radiation interaction studies is introduced in this paper. It consists of a Learjet 35A research aircraft and the AIRcraft TOwed Sensor Shuttle (AIRTOSS), which is an instrumented drag-body towed by the Learjet. Currently, the AIRTOSS is instrumented with a Cloud Imaging Probe (CIP) for measuring cloud microphysical properties and an Inertial Navigation System (INS) for measurements of flight attitudes. The cable dragging AIRTOSS can be as long as four kilometres. Thus, truly collocated measurements in two altitudes above, in, and below clouds can be obtained. Results from first test flights with Learjet and AIRTOSS are reported here. The flights were performed from Hohn Airport, Germany. Specific manoeuvres were flown to test the aerodynamic behaviour of the drag-body and to investigate the suitability of AIRTOSS for high-precision irradiance measurements which require a stable flight attitude of AIRTOSS. The flight attitude data show that AIRTOSS is sensitive to several flight manoeuvres such as turns, altitude and airspeed changes, and also to changes of towing cable length. The effects of these manoeuvres on the attitude angles of AIRTOSS have been quantified. Maximum roll angle deviations were observed during turns. Even small changes in heading can lead to high roll angles (one degree change in heading causes a change in roll angle of about eight degrees). The pitch angle varies during climb or dive periods, extending or retracting of towing cable, acceleration or deceleration, and even when flying at too low or too high true airspeed depending on altitude. Values of pitch angle between $-5^{\circ}$ (dive) and $8^{\circ}$ (climb and retracting towing cable) have been observed. While change in attitude
\end{abstract}

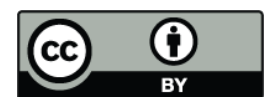

Correspondence to: W. Frey

(freyw@uni-mainz.de) is not problematic for cloud particle property measurements it is for radiation measurements. Here, the deviation from the horizontal should be no more than $3^{\circ}$ to avoid large errors. When keeping the above mentioned flight parameters constant, sufficiently stable flight conditions can be maintained to perform high-quality irradiance measurements with AIRTOSS in future experiments. During this test campaign also observations of cloud microphysical data as for example droplet number concentrations and size distributions with the AIRTOSS in stratocumulus clouds were performed to prove the compliance with scientific needs. Simultaneous spectral cloud radiation measurements have been made. The measurements of internal operational data of AIRTOSS as well as the first atmospheric data demonstrate the suitability of this tandem platform for detailed cloud microphysics and radiation interaction studies.

\section{Introduction}

Clouds constitute an important factor in the global climate since they affect the radiation balance of the Earthatmosphere system in complicated but significant ways (cooling and warming of the atmosphere, as discussed in the IPCC report (Solomon et al., 2007)). Widely varying cloud micro- and macrophysical properties lead to high variability in the radiative impact of clouds which makes it hard to parameterise their influence on Earth's radiation budget. In order to investigate the link between cloud micro- and macrophysical properties by in-situ measurements it is highly desirable to assure simultaneous observations of microphysical particle properties within the clouds and radiation measurements above and beneath the clouds. So far this has been

Published by Copernicus Publications on behalf of the European Geosciences Union. 
attempted by using several aircraft in stack during numerous airborne experiments such as the Cirrus Regional Study of Tropical Anvils and Cirrus Layers - Florida Area Cirrus Experiment (CRYSTAL-FACE, Jensen et al., 2004) or the Tropical Composition, Cloud and Climate Coupling $\left(\mathrm{TC}^{4}\right)$ mission (Toon, 2007). These attempts of collocated airborne sampling have only partly been successful.

There are serious practical difficulties encountered when using more than one aircraft in cloudy atmospheres: Tight flight safety regulations complicate the coordination of the aircraft, especially for close proximity of aircraft. It seems almost impossible to obtain truly synchronised measurements when aircraft are flying at different speeds. In addition, flying with several aircraft is rather expensive.

Therefore, a new tandem measurement constellation has been developed, consisting of two instrumental carriers: a Learjet 35A research aircraft and the AIRcraft TOwed Sensor Shuttle (AIRTOSS). AIRTOSS is a sensor pod which is attached to a winch under the aircraft wing. It can be detached from, towed by, and retracted onto the Learjet. The Learjet is presently mainly equipped with radiation instruments, while the AIRTOSS currently carries instrumentation to measure cloud microphysical properties. Towing cable length and airspeed can be varied to adapt for different vertical profile measurements. The position of the AIRTOSS can be controlled such that it stays away from the exhaust or contrail of the Learjet. With this novel tandem setup truly collocated measurements in and around clouds can be performed for the first time.

\section{AIRTOSS/Learjet tandem: implemented instrumen- tation}

The sensor locations of the instruments within the tandem measurement constellation is shown in Fig. 1. The instruments and their technical specifications are listed in Table 1.

\subsection{AIRTOSS}

The empty drag-body of AIRTOSS (see Fig. 1a) is $2.57 \mathrm{~m}$ long, has a diameter of $0.24 \mathrm{~m}$ and a weight of $27 \mathrm{~kg}$. With the Cloud Imaging Probe (CIP) installed the length is $2.85 \mathrm{~m}$. AIRTOSS has a maximum payload of $43 \mathrm{~kg}$ and thus, maximum weight of $70 \mathrm{~kg}$. During the campaign the weight of the fully equipped AIRTOSS was $54.2 \mathrm{~kg}$, see Table 2 for details. This table also shows the power consumption of the different devices (see at the end of this section) and the rough centres of gravity for the devices. The centre of gravity of the fully equipped AIRTOSS is located $50 \mathrm{~mm}$ behind the hook to keep the AIRTOSS in a horizontal position during flight. In Fig. 2 a sketch of AIRTOSS with the positions of the instruments, batteries, and computer is presented. An Inertial Navigation System (INS) is installed in the rear part of the drag-body to measure the attitude angles (roll, pitch,

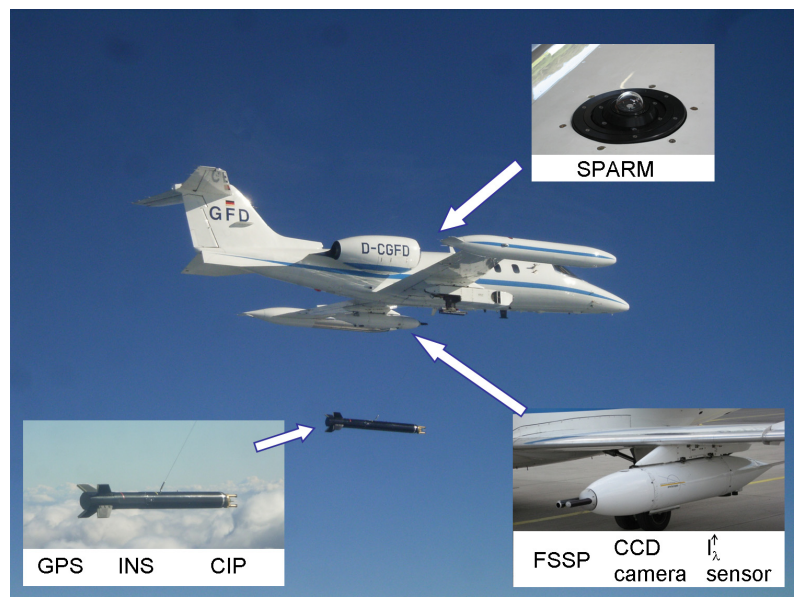

(a) Learjet with detached AIRTOSS along with placement of instruments.

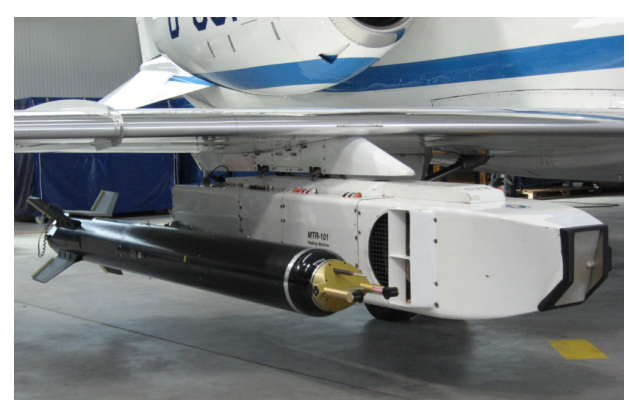

(b) AIRTOSS connected to the winch under the right wing of the aircraft.

Fig. 1. The new airborne tandem measurement platform consisting of the Learjet 35A aircraft and the instrumented AIRcraft Towed Sensor Shuttle (AIRTOSS).

and heading) and accelerations. For measuring the exact position a Global Positioning System (GPS) is placed in front of the INS. The CIP is located at the tip of AIRTOSS. It delivers 2-dimensional shadow images of cloud particles in a size range of $25-1600 \mu \mathrm{m}$ in diameter (Baumgardner et al., 2001). Thus, particle shapes, particle size distributions, and number concentrations are obtained from the CIP measurements. Power supply for the AIRTOSS devices is provided by batteries. During the test campaign 22 batteries with a nominal voltage of $1.2 \mathrm{~V}$ and capacitance of $15 \mathrm{Ah}$ which are connected in series are used. With an estimated consumption of $26 \mathrm{~V}$ at a current of $8.35 \mathrm{~A}$ the batteries are running for about one hour and $48 \mathrm{~min}$. Table 2 shows how power consumptions of AIRTOSS devices are distributed.

\subsection{Learjet instrumentation}

The winch for the AIRTOSS is installed beneath the right wing of the Learjet as shown on Fig. 1b. An instrumented wingpod is attached to the left wing (see Fig. 1a), further instruments are installed on top of the fuselage. Here, the 
Table 1. Specification of instruments and measured properties.

\begin{tabular}{lll}
\hline Instrument (position) & Measured property & Technical specifications \\
\hline CIP (AIRTOSS) & $\begin{array}{l}\text { cloud particle size, shape, } \\
25<\mathrm{Dp}<1600 \mu \mathrm{m}\end{array}$ & resolution: $25 \mu \mathrm{m}$; sample rate: $8 \mathrm{MHz}$ \\
\hline FSSP (Learjet) & $\begin{array}{l}\text { cloud particle size distribution, } \\
2<\mathrm{Dp}<47 \mu \mathrm{m}\end{array}$ & response time: $0.7 \mu$ s; sample rate: $1 \mathrm{~Hz}$ \\
& $\begin{array}{l}\text { downwelling irradiance }\left(F_{\lambda}^{\downarrow}\right), \\
\text { VIS and NIR spectrom- }\end{array}$ & $\begin{array}{l}\text { resolution: } 2-3 \mathrm{~nm} \text { for } 350<\lambda<1000 \mathrm{~nm}, 9-16 \mathrm{~nm} \\
\text { for } 1000<\lambda<2200 \mathrm{~nm} \text {; sample rate: } 0.15-10 \mathrm{~Hz}\end{array}$ \\
eter (Learjet) & $350<\lambda<2200 \mathrm{~nm}$ & $($ VIS), $0.65-10 \mathrm{~Hz}(\mathrm{NIR})$ \\
\hline VIS and NIR spectrom- & upwelling radiance $\left(I_{\lambda}^{\uparrow}\right)$, & \\
\hline eter (Learjet) & $350<\lambda<2200 \mathrm{~nm}$ & Pixel clock rate: $25 \mathrm{MHz}$ \\
\hline CCD camera (Learjet) & $2-\mathrm{D}$ cloud images, $\lambda \approx 550,660$, and \\
& $800 \mathrm{~nm}$ & sample rate: $10 \mathrm{~Hz} ;$ position accuracy: \\
\hline GPS (AIRTOSS) & position & $0.75-5 \mathrm{~m} \mathrm{CEP}$ \\
\hline INS (AIRTOSS) & attitude angles & $\begin{array}{l}\text { resolution: }<0.01^{\circ} \mathrm{s}-1 ; \text { accuracy: }<0.3^{\circ} ; \text { sample } \\
\text { rate: } 100 \mathrm{~Hz}\end{array}$ \\
\hline
\end{tabular}

Table 2. Weights, rough centre of gravity, and estimated power consumptions of AIRTOSS devices. Centre of gravity (c.g.) is measured from hook in flight direction.

\begin{tabular}{lrrr}
\hline Device & Weight $(\mathrm{kg})$ & $\begin{array}{r}\text { centre of } \\
\text { gravity }(\mathrm{mm})\end{array}$ & $\begin{array}{r}\text { Power } \\
\text { consumption (W) }\end{array}$ \\
\hline Structure & 26.55 & -172.51 & \\
CIP & 7.75 & 1028.00 & 100 \\
Battery 1 & 6.45 & 130.00 & \\
Battery 2 & 5.50 & & \} 58 \\
INS/GPS & 3.65 & -565.40 & 50 \\
Telemetry & 1.80 & -1200.00 & 9 \\
Data acquisition & 0.21 & -75.00 & 217 \\
Periphery & 0.30 & & \\
Antenna & 54.21 & -50.22 & \\
\hline Total & & & \\
\hline
\end{tabular}

Stabilized Platform for Airborne Radiation Measurements (SPARM) is used for horizontal stabilisation of the spectral irradiance sensor which, in the current configuration, measures downwelling irradiance $\left(F_{\lambda}^{\downarrow}\right)$ in a wavelength-range of $350-2200 \mathrm{~nm}$. A description of the stabilisation platform as well as the radiation sensors is given in Wendisch et al. (2001). A sensor to measure spectral upwelling radiances $\left(I_{\lambda}^{\uparrow}\right)$ also covering the wavelength-range of $350-2200 \mathrm{~nm}$ is installed in the wingpod. A digital, multispectral 2-D CCD camera (DuncanTech, 2002) is installed in the middle of the wingpod and looks downward with a viewing angle of 58.1 . It measures upwelling radiances in the green $(550 \mathrm{~nm})$, red $(660 \mathrm{~nm})$, and near-infrared $(880 \mathrm{~nm})$ wavelength ranges. At the front of the wingpod a Forward Scattering Spectrometer

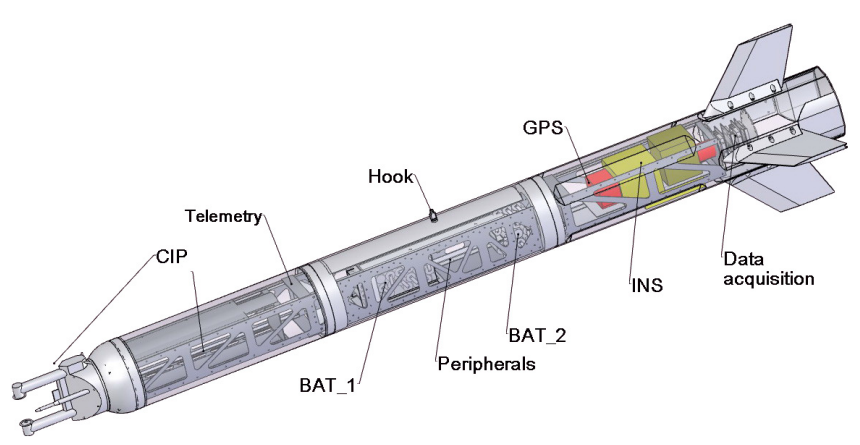

Fig. 2. Schematics of AIRTOSS with specifications of the sensor positions. The total length is $2.85 \mathrm{~m}$ with a diameter of $0.24 \mathrm{~m}$. Radiation sensors shall be implemented in the area of GPS/INS.

Probe (FSSP-100) is installed to measure cloud particle size distributions in the size range of 2-47 $\mu \mathrm{m}$ (Dye and Baumgardner, 1984).

\section{Proof-of-concept campaign}

A first measurement campaign with the AIRTOSS has been conducted in September 2007 from Hohn Airport, Northern Germany. Main questions for this campaign were:

- Does the fully instrumented AIRTOSS maintain a stable flight attitude (no tumbling, rolling, pitching, etc.) during specific aircraft manoeuvres? 
- Is it possible to perform in cloud measurements with sufficient accuracy for an extended time period with the AIRTOSS?

- Is it possible to obtain collocated measurements of cloud microphysical particle properties and radiation with the tandem measurement platform?

- How strong are the vibrations/motions of AIRTOSS during level flight and flight manoeuvres? And thus,

- Is AIRTOSS suited for integration of radiation sensors, i.e. are attitude variations small enough to allow for accurate radiation measurements?

Three test flights of about two hours each have been performed with the tandem measurement platform. The flight area was located above the North Sea west of SchleswigHolstein, Germany. In order to closely watch the flight behaviour of AIRTOSS the first flight was accompanied by a second Learjet in clear air. The two following flights included measurements where AIRTOSS was released into a low marine stratocumulus cloud layer. The tests were performed at different Learjet altitudes up to $7620 \mathrm{~m}$ and true airspeeds varying between 90 and $205 \mathrm{~m} \mathrm{~s}^{-1}$. While the towing cable was kept short (about $150 \mathrm{~m}$ ) when the AIRTOSS was dipped into clouds, manoeuvres were flown with towing cable length up to $4 \mathrm{~km}$. Due to flight safety regulations when AIRTOSS is not attached to the winch all tests were carried out within military controlled air space. Flying through mixed-phase clouds with AIRTOSS detached is prohibited due to possible icing on the drag-body or towing cable.

\subsection{Integration of radiation sensors onto AIRTOSS}

Since clouds are not only reflecting solar radiation back to space but also emit thermal infrared radiation back down to earth, it is planned to integrate spectral radiation sensors onto AIRTOSS. This will allow concurrent spectral radiation measurements with AIRTOSS underneath or within the cloud and Learjet in or above the cloud. Since the towing cable is twisted in a way to assure that the AIRTOSS will stay away sideways from the Learjet, radiation measurements on AIRTOSS will not be affected by the Learjet's contrail. Accurate horizontal alignment of the radiation sensors is crucial for exact irradiance measurements since these are related to a horizontal coordinate system. The effects of horizontal misalignment of sensor heads on irradiance measurements (direct portion only) in clear sky conditions (above cloud) have been discussed by Wendisch et al. (2001). The deviation of direct irradiance increases with increasing horizontal misalignment and increasing solar zenith angle. For example, a $1.0^{\circ}$ horizontal misalignment at solar zenith angles of $20^{\circ}, 40^{\circ}$, and $60^{\circ}$ cause deviations of irradiance of $-0.7 \%,-1.5 \%$, and $-3.0 \%$. Since AIRTOSS is intended for flying below or within clouds, similar calculations were made for the influence of horizontal misalignment on irradiance below cirrus including diffuse radiation. Different solar azimuth angles (SAA) and solar zenith angles (SZA), cirrus optical thicknesses ( $\tau=1$ and $\tau=7$ ), and wavelengths $(500 \mathrm{~nm}, 670 \mathrm{~nm}$, and $1600 \mathrm{~nm}$ ) have been chosen as input parameters for these calculations. As a result we find that the main misalignment related uncertainties of downwelling irradiances are:

1. independent of SAA,

2. only weekly dependent on wavelengths of the solar radiation,

3. strongly influenced by SZA: the higher SZA the higher the uncertainty, and

4. to some extend dependent on cirrus optical thickness: Except for very high SZA $\left(70-80^{\circ}\right)$ increasing optical thickness resulted in higher downwelling irradiance uncertainties.

Figure 3 displays the misalignment related uncertainties for downwelling irradiances at $500 \mathrm{~nm}$ wavelength below cirrus with an optical thickness of $\tau=1$. It clearly shows the dominant dependence of percental deviation of downwelling irradiance on the solar zenith angle. In order to keep misalignment related errors tolerable, a maximum tolerable horizontal misalignment of $3^{\circ}$ is estimated. It should be emphasised that this is valid for conditions when diffuse radiation dominates the radiation field. For a solar zenith angle of $40^{\circ}$ this $3^{\circ}$ limit will keep the deviation of irradiance below $5 \%$ above clouds and slightly over 5\% below clouds for thin cirrus $(\tau=1)$. For cirrus with an optical thickness of 7 the deviation will be $6.8 \%$ for $500 \mathrm{~nm}$ wavelength. However, it should be kept in mind that cirrus is mostly optically thin. This has been shown, e.g., by Giannakaki et al. (2007) who found the prevailing values for cirrus optical thicknesses between 0.2 and 0.3 using lidar measurement techniques. Lynch (2002) gives a range of cirrus optical thicknesses of 0.03-3.0 (without subvisible cirrus). In some cases of small cirrus patches, e.g. cirrus formed by deep convection, this upper limit can be exceeded.

\section{In-flight measurements of AIRTOSS parameters and atmospheric observations}

Throughout the test campaign a stable high pressure area was located over Ireland. Weak winds (about $5 \mathrm{~m} \mathrm{~s}^{-1}$ at ground, maximum $25 \mathrm{~m} \mathrm{~s}^{-1}$ at flight level) were prevailing from northerly directions.

\subsection{AIRTOSS attitude stability}

Important for a safe flight with the AIRTOSS is that the drag-body does not perform strong tumbling motions. Even 


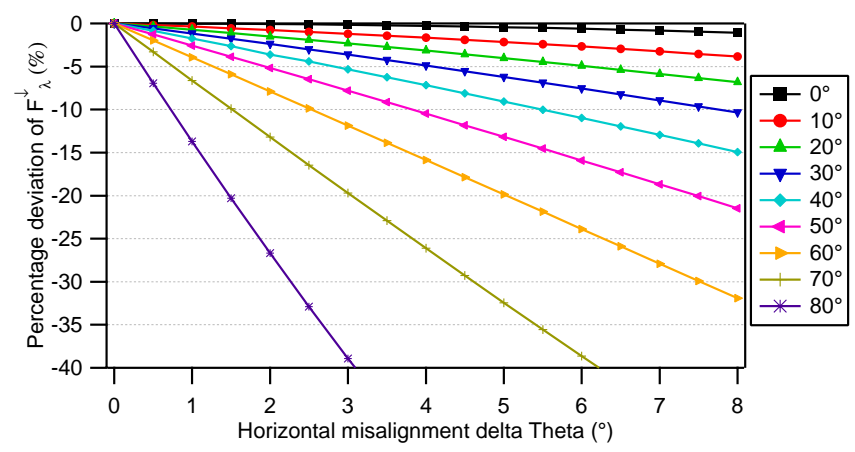

Fig. 3. Percentage of deviation of downwelling irradiance at $500 \mathrm{~nm}$ as a function of horizontal misalignment $\Delta \Theta$ for different values of solar zenith angle below cirrus with $\tau=1$.

though small changes in attitude angles should not affect measurements of the CIP, stable flight conditions are crucial for irradiance sensors which are planned to be integrated onto the AIRTOSS as mentioned in Sect. 3.1.

The observations from the nearby flying Learjet during the first test flight on 4 September 2007 showed that the AIRTOSS executed no visible vibrations or significant roll, pitch, and yaw movements. During the two flights on 6 and 7 September 2007 about 70 min of continuous data from INS, GPS, CIP, and radiation sensors were acquired for analysis. Several test manoeuvres were performed during the flight on 6 September 2007 when the Learjet changed altitude, airspeed, and towing cable length. The results are displayed in Fig. 4 together with the Learjet altitude and true airspeed (TAS) in the upper panel and the attitude angles of AIRTOSS in the lower panel. Various effects of the different aircraft manoeuvres are obvious in the attitude angles. On 7 September 2007 the Learjet flew several legs through low marine stratocumulus at almost constant altitude and airspeed. The data of both flights have been split into different groups of flight phases such as constant conditions flight phase, turns, and different manoeuvres. During these phases the impact of changes in the flight parameters, such as altitude, airspeed, towing cable length, and attitude angles of AIRTOSS, named $x$ and $y$ in Eq. (1), are investigated. Pearson correlation coefficients of these flight parameters have been calculated according to the following equation:

$r_{x y}=\frac{\operatorname{COV}_{x y}}{s_{x} s_{y}}=\frac{\sum_{i=1}^{n}\left(x_{i}-\bar{x}\right)\left(y_{i}-\bar{y}\right)}{(n-1) s_{x} s_{y}}$

with $\mathrm{COV}_{x y}$ being the covariance between $x$ and $y, s_{x}$ and $s_{y}$ denoting the sample standard deviations of $x$ and $y$, and $\bar{x}$ and $\bar{y}$ referring to the sample means of $x$ and $y$. The number of data points recorded at $1 \mathrm{~Hz}$ resolution for the calculation varies with the flight phases and is given in Table 3 . The minimum/mean number of data points was 169/910, respectively. With these numbers of data points all correlations which are
Table 3. Flight information for calculation of the correlation coefficients for the different flight phases.

\begin{tabular}{lrc}
\hline Phase & $\begin{array}{r}\text { Number of } \\
\text { data points }\end{array}$ & Flight date \\
\hline All & 2321 & 6 September 2007 \\
All & 1898 & 7 September 2007 \\
Constant conditions & 169 & 6 September 2007 \\
Constant conditions & 874 & 7 September 2007 \\
Turns & 643 & 7 September 2007 \\
Turns plus decay time & 905 & 7 September 2007 \\
TAS change & 687 & 6 September 2007 \\
Altitude change & 1029 & 6 September 2007 \\
Towing cable length change & 251 & 6 September 2007 \\
Circle cases & 323 & 6 September 2007 \\
\hline
\end{tabular}

specified in the following are significant with absolute values of $r_{x y}$ ranging from 0.74 to 0.99 . Examples for correlations can be seen in Fig. 5.

\subsubsection{General findings}

Some statements can be made for all flight phases. The AIRTOSS heading is generally following the Learjet heading with a delay which depends on towing cable length. The delay amounts to $14 \mathrm{~s}$ for a $150 \mathrm{~m}$ long towing cable (flight on 7 September 2007 and begin of flight on 6 September 2007) and $35 \mathrm{~s}$ for a $4000 \mathrm{~m}$ long cable (second half of the flight on 6 September 2007).

The roll angle is sensitive to changes in heading when flying turns (in the following, 'turn' refers to any curved flight trajectory). For the flights on 6 and 7 September 2007 the correlation coefficient between AIRTOSS heading change and roll angle is 0.96 and 0.97 , respectively, including 2321 and 1898 data points. The correlation for the flight on 7 September 2007 is shown in Fig. 5a. Furthermore, the roll angle is always slightly negative due to the fact that AIRTOSS stays away sideways from the Learjet. Thus, when AIRTOSS is flying slightly on the right side of the Learjet the towing cable causes an additional force component on AIRTOSS to the left.

\subsubsection{Constant conditions flight}

Constant conditions flight phases are defined as measurement periods where no apparent changes in TAS, altitude, and towing cable length are performed, no turns are flown, and also a decent time after turns, called decay time, is excluded from the data due to influences of turns on flight behaviour. How this decay time is determined is described in detail in the following section, for the analysis here the observed values which can be found in Table 4 are taken. Two time periods were examined from the data of 6 September 2007 (53 005$53127 \mathrm{~s}$ UTC and 54 049-54 $124 \mathrm{~s}$ UTC), corresponding to a low and high altitude situation at a Learjet altitude of about 


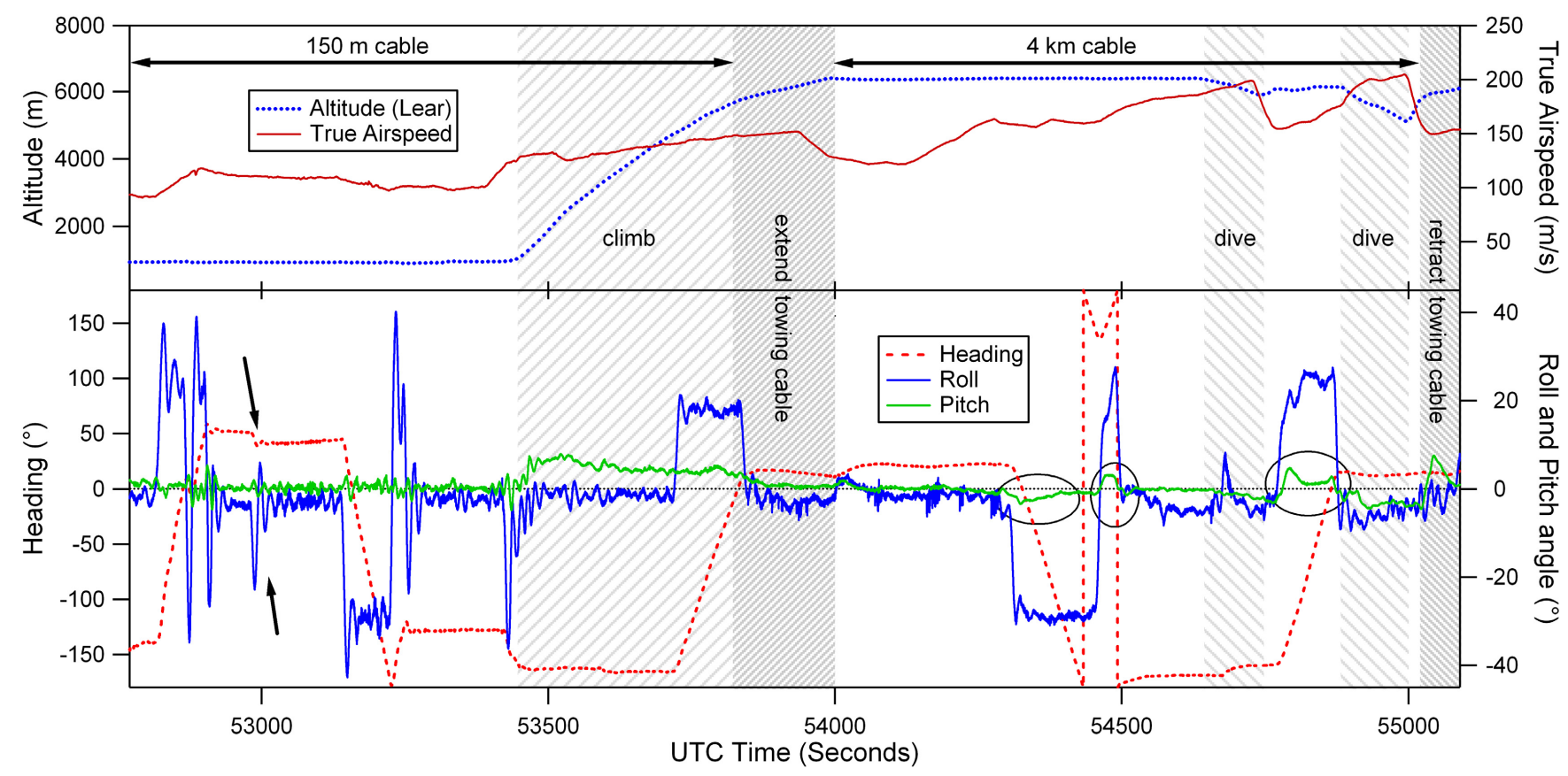

Fig. 4. Flight parameters on 6 September 2007. Learjet altitude and TAS are displayed in the upper panel, AIRTOSS attitude angles in the lower panel. Several manoeuvres as analysed in Sect. 4 are indicated.

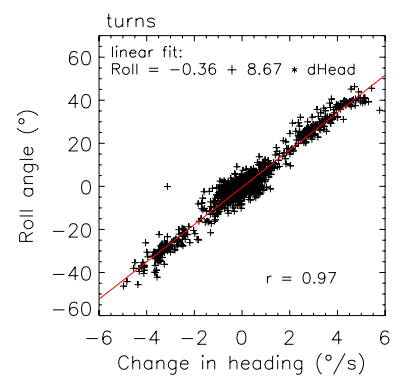

(a) Correlation between changes in AIRTOSS heading and roll angle.

Fig. 5. Examples for correlations between different flight parameters on the flight on 7 September 2007.

$930 \mathrm{~m}$ and $6350 \mathrm{~m}$, respectively. For 7 September 2007, several periods of straight flight legs at an altitude of about $660 \mathrm{~m}$ were considered. During the latter periods a correlation coefficient of -0.85 between TAS and pitch angle was found. The regression shown in Fig. $5 \mathrm{~b}$ indicates that there is an optimum speed of about $105 \mathrm{~m} \mathrm{~s}^{-1}$ to keep the AIRTOSS horizontal in this case. For an AIRTOSS altitude of about $500 \mathrm{~m}$, as on this flight, TAS should be kept in a range of $80-130 \mathrm{~m} \mathrm{~s}^{-1}$ to stay within the tolerable limit for pitch angle variations of $3^{\circ}$. AIRTOSS needs a specific air resistance to stay in a horizontal position which is achieved by flying at
Table 4. Table of decay times of roll angle after turns flown on 7 September 2007.

\begin{tabular}{lcc}
\hline Turn & $\tau\left(3^{\circ}\right)(\mathrm{s})$ & Heading/wind difference $\left({ }^{\circ}\right)$ \\
\hline $\mathrm{t} 1$ & 49 & 70 \\
$\mathrm{t} 2$ & 51 & -120 \\
$\mathrm{t} 3$ & 36 & -90 \\
$\mathrm{t} 4$ & 22 & 100 \\
$\mathrm{t} 5$ & 55 & 60 \\
$\mathrm{t} 6$ & 32 & -105 \\
$\mathrm{t} 7$ & 38 & 90 \\
$\mathrm{t} 8$ & 37 & -110 \\
$\mathrm{t} 9$ & 44 & -95 \\
$\mathrm{t} 10$ & 38 & \\
\hline$\varnothing$ & 40.2 & \\
\hline
\end{tabular}

an optimum speed. Since air resistance changes with air density and thus with altitude, also this optimum speed changes with altitude. If the air resistance is too small, caused by too low airspeed, the pitch angle becomes positive which means that the front section of AIRTOSS faces downward. For a too high air resistance the pitch angle becomes negative, respectively.

Similar calculations have been made for the two constant conditions flight periods on 6 September 2007. These give an estimate of optimum TAS of $110 \mathrm{~m} \mathrm{~s}^{-1}$ for an AIRTOSS 
Table 5. Summary table of AIRTOSS flight behaviour during the flight manoeuvres on 6 September 2007. Whether the parameters are within the chosen accuracy limit for radiation measurements is denoted by y (yes) or $\mathrm{n}$ (no) between the minimum and maximum values.

\begin{tabular}{|c|c|c|c|c|c|}
\hline \multirow[b]{2}{*}{ Flight phase } & \multicolumn{5}{|c|}{ minimum and maximum value of } \\
\hline & $\begin{array}{l}\operatorname{Pitch}^{A}\left({ }^{\circ}\right) \\
\operatorname{Roll}^{A}\left({ }^{\circ}\right)\end{array}$ & $\begin{array}{l}\text { Heading change }{ }^{A} \\
\left({ }^{\circ} \mathrm{s}^{-1}\right)\end{array}$ & $\begin{array}{c}\mathrm{TAS}^{L} \\
\left(\mathrm{~m} \mathrm{~s}^{-1}\right)\end{array}$ & $\begin{array}{c}\text { Acceleration } \\
\left(\mathrm{m} \mathrm{s}^{-2}\right)\end{array}$ & $\begin{array}{l}\text { Altitude }^{A}(\mathrm{~m}) \\
\text { Altitude }^{L}(\mathrm{~m})\end{array}$ \\
\hline $\begin{array}{l}\text { Constant conditions } \\
\text { low }\end{array}$ & $\begin{array}{l}-0.91<\mathrm{y}<1.15 \\
-5.06^{\mathrm{a}}<\mathrm{n}<-0.57\end{array}$ & $-0.84<\mathrm{n}<1.07$ & $107.7<-{ }^{b}<109.8$ & $-0.99<y<0.99$ & $\begin{array}{l}756<-<766 \\
927<-<934\end{array}$ \\
\hline $\begin{array}{l}\text { Constant conditions } \\
\text { high }\end{array}$ & $\begin{array}{l}-0.61<y<0.68 \\
-2.72<y<0.39\end{array}$ & $-0.27<y<0.23$ & $121.6<-<123.6$ & $-0.41<y<0.36$ & $\begin{array}{l}5900<-<5952 \\
6350<-<6361\end{array}$ \\
\hline Climb (without turns) & $\begin{array}{r}3.27<\mathrm{n}<7.79 \\
-4.64<\mathrm{n}<1.47\end{array}$ & $-0.46<\mathrm{n}<0.44$ & $125.1<-<140.7$ & $-1.0<\mathrm{y}<0.73$ & $\begin{array}{l}1426<-<4237 \\
1876<-<4702\end{array}$ \\
\hline Dive & $\begin{array}{l}-4.39<\mathrm{n}<-0.12 \\
-8.93<\mathrm{n}<2.72\end{array}$ & $-0.21<y<0.29$ & $176.1<-<204.8$ & $-1.64<y<0.67$ & $\begin{array}{l}5264<-<6204 \\
5112<-<6379\end{array}$ \\
\hline Towing cable extend ${ }^{c}$ & $\begin{array}{c}0.18<\mathrm{n}<3.66 \\
-4.85<\mathrm{n}<19.27\end{array}$ & $-0.37<\mathrm{n}<1.78$ & $127.8<-<151.9$ & $-0.73<\mathrm{y}<0.35$ & $\begin{array}{l}5210<-<5916 \\
5645<-<6394 \\
\end{array}$ \\
\hline Towing cable retract & $\begin{array}{l}-4.5^{\mathrm{d}}<\mathrm{n}<7.48 \\
-6.93<\mathrm{n}<6.97\end{array}$ & $-0.31<\mathrm{n}<0.5$ & $149.4<-<161.6$ & $-1.41<\mathrm{y}<0.42$ & $\begin{array}{l}4976<-<5697 \\
5746<-<6094\end{array}$ \\
\hline $\begin{array}{l}\text { TAS change (rather } \\
\text { undisturbed) }\end{array}$ & $\begin{array}{c}-4.03<\mathrm{n}<1.3 \\
-10.98<\mathrm{n}<1.01\end{array}$ & $-0.72<\mathrm{n}<0.75$ & $100.6<-<204.8$ & $-2.64<\mathrm{n}<1.03$ & $\begin{array}{l}778<-<6089 \\
947<-<6391 \\
\end{array}$ \\
\hline Circle cases & $\begin{array}{c}-3.38<\mathrm{n}<4.66 \\
-30.19<\mathrm{n}<26.88\end{array}$ & $-1.84<\mathrm{n}<2.07$ & $154.4<-<175.3$ & $-0.67<y<0.71$ & $\begin{array}{l}5659<-<6205 \\
6036<-<6398\end{array}$ \\
\hline
\end{tabular}

A/L AIRTOSS/Learjet variable;

a high oscillations in this phase, possibly due to turbulences;

$\mathrm{b}$ optimum TAS is height dependent, therefore, no statement could be given here;

c concurrent with climbing of the Learjet;

$\mathrm{d}$ low value resulting from preceding dive period

altitude of $760 \mathrm{~m}$ and $120 \mathrm{~m} \mathrm{~s}^{-1}$ for $5910 \mathrm{~m}$. Unfortunately, no further measurements were made in more different altitudes, thus, no significant correlation in terms of a general equation can be given.

To see how steady the AIRTOSS flight behaviour is during constant conditions flight phases, standard deviations of changes in roll and pitch angle have been calculated for the given time periods on 6 September 2007. For the low altitude situation (about $800 \mathrm{~m}$ ) these standard deviations are $0.61^{\circ}$ for roll and $0.27^{\circ}$ for pitch angle. At higher altitude (about $6000 \mathrm{~m}$ ) they reduce to $0.4^{\circ}$ and $0.14^{\circ}$, respectively. This seems to be the effect of boundary layer turbulences. Especially pitch angle oscillations smooth out during/after climbing to higher altitudes. The minimum and maximum pitch angle during these time periods is $-0.91^{\circ}$ and $1.15^{\circ}$ at low altitude, and $-0.61^{\circ}$ and $0.68^{\circ}$ at high altitude, respectively. These and further minimum and maximum values for the different flight phases are listed in Table 5.

\subsubsection{Turns}

On 7 September 2007 the Learjet flew some legs through low marine stratocumulus at almost constant altitude and airspeed $\left(\sim 650 \mathrm{~m}\right.$ and $\left.\sim 100 \mathrm{~m} \mathrm{~s}^{-1}\right)$. After each turn the oscillation of roll angle increased. This increase occurred even after slight turns as pointed out by the arrows at about $53000 \mathrm{~s}$ UTC in Fig. 4. Since flight conditions were mostly constant on 7 September 2007, these data are used to determine the time which is needed to recover from flying turns and return to stable attitude. This time is called decay time. Ten turns were flown during the data acquisition period, numbered t 1 through $\mathrm{t} 10$. Table 4 shows the decay times of the diminishing oscillations until roll angle values stay between $-3^{\circ}$ and $3^{\circ}$. Decay times are counted beginning at the end of Learjet heading change until the first AIRTOSS roll angle zero line crossing after which the absolute value of roll angle does not exceed $3^{\circ}$. Thus, the decay time includes the delay of AIRTOSS attitude angles to Learjet heading. AIRTOSS heading, and thus, roll angle is $14 \mathrm{~s}$ late in this case but the delay changes with towing cable length and so will the decay time. Three degree have been chosen as mentioned in Sect. 3.1 in order to keep the misalignment related errors of radiation measurements tolerably small. Also the difference between AIRTOSS heading and wind direction measured on the Learjet are given in $5^{\circ}$ steps. Negative values in the difference denote a wind from the left, $0^{\circ}$ wind from the front. The wind direction in Learjet and AIRTOSS altitude should be nearly the same, since towing cable length during 


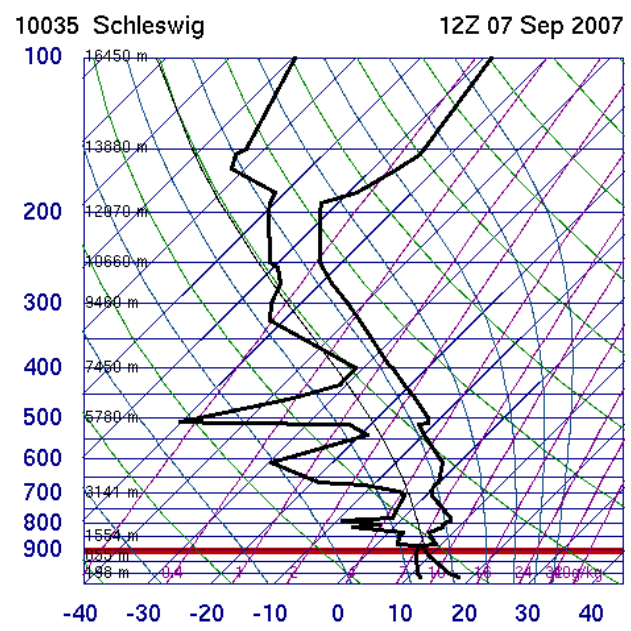

(a) Sounding from Schleswig on 7 September 2007, 12:00 UTC, taken from University of Wyoming. The black lines show dew-point temperature (left) and temperature (right), the red band indicates the cloud layer.

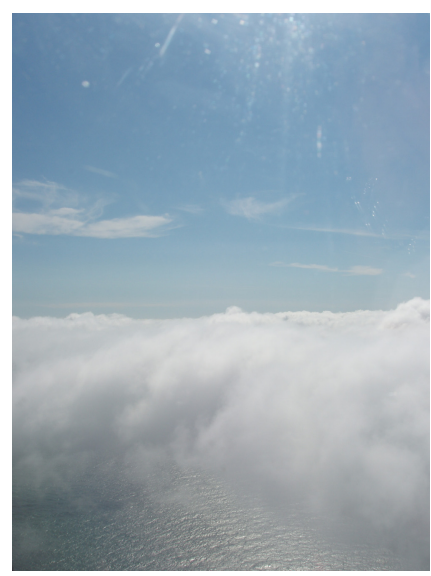

(b) Photograph of cloud layer in which the AIRTOSS was dipped.

Fig. 6. Meteorological situation on 7 September 2007 during the cloud legs.

the cloud legs is about $150 \mathrm{~m}$. This can also be assessed from Fig. 6a, which shows a sounding from Schleswig circa $30 \mathrm{~km}$ north of Hohn. Wind barbs are displayed on the right hand side. They do not show a significant change in wind direction in the relevant altitudes. During the cloud legs the AIRTOSS was faced with winds from the side, as Table 4 shows. This might enhance the oscillations after the turns and thus, increase the decay time. The arithmetic mean of the decay times of the 10 turns has been calculated. It amounts to $40 \mathrm{~s}$ and includes the $14 \mathrm{~s}$ delay of AIRTOSS to Learjet at $150 \mathrm{~m}$ cable length. At the time of $\mathrm{t} 1$ some turbulences have been observed on the Learjet. These turbulences may have caused the somewhat longer decay time of $49 \mathrm{~s}$. At $43500 \mathrm{~s}$ UTC pitch angle variations with the Learjet were performed. This applies to $\mathrm{t} 9$ and $\mathrm{t} 10$ but the respective decay times are still close to the average.

Generally, AIRTOSS should be stable $30 \mathrm{~s}$ after turns when flying in the boundary layer plus the respective delay of AIRTOSS attitude to Learjet. This value might reduce in higher altitudes, unfortunately no measurements in other altitudes under similar conditions have been made to confirm this assumption.

\subsubsection{Turns with long towing cable (Circle cases)}

Flying turns at higher altitudes ( $\sim 6350 \mathrm{~m}$ Learjet) with high TAS (150-200 $\mathrm{m} \mathrm{s}^{-1}$ ) and with long towing cable $(4 \mathrm{~km})$ shows some interesting behaviour: Stronger forces seem to be effective on AIRTOSS during these periods which are marked with circles in Fig. 4. The pitch angle follows the roll angle and heading, correlations of both 0.83 are found whereas no correlation of these parameters are observed dur- ing the selected periods $t 1$ to 10 on the flight on 7 September 2007. During these periods pitch angle becomes positive in a right turn and negative in a left turn. For a possible explanation the winch position under the right wing and the fact that the drag-body stays away sideways to the right has to be remembered. In a right turn AIRTOSS will take up a position inside the circle which is described by the flight path of the Learjet. Here, AIRTOSS has to cover a shorter distance than the Learjet and thus, will fly at a lower speed, having a lower air resistance which in turn will lead to a positive pitch angle, see Sect. 4.1.2. In left turns stronger centrifugal forces are active and thus, the circle described by the AIRTOSS flight path is larger than the circle described by the Learjet flight path. This forces AIRTOSS to fly at a higher speed causing higher air resistance and therefore, causing a negative pitch angle. In case of the $150 \mathrm{~m}$ long towing cable this behaviour should be present as well but the effects are too small to be observed here. The forces generated by the radii of the turns are not as strong.

\subsubsection{True Airspeed (TAS) change}

Four periods including Learjet TAS changes have been selected from the flight on 6 September 2007 during which other flight parameters stay preferably constant (altitude, towing cable length, straight on flight). In two periods the TAS continuously increased (accelerated flight: 5338953424 and $54136-54277$ s UTC) whereas in two flight periods the TAS was decreased (decelerated flight: 5474554771 and 54994-55019s UTC). Here, correlations between TAS and pitch angle as well as acceleration and pitch angle were found. The respective correlation coefficients 


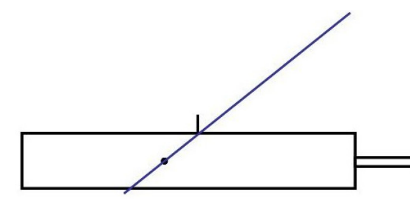

normal

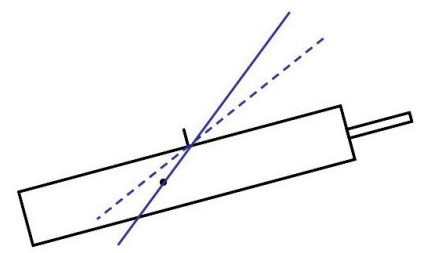

decelerated

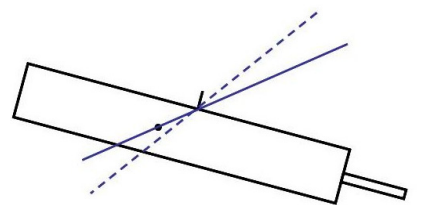

accelerated

Fig. 7. Effects of centre of gravity on acceleration or deceleration of the aircraft on AIRTOSS. Dashed lines indicate the towing cable position in the case of constant speed = normal flight. A description is given in Sect. 4.1.5.

were -0.74 and 0.84 . If more parameters change at the same time these effects are less visible, especially for cases when turns are flown. The correlation of TAS and pitch angle has been discussed above in Sect. 4.1.2. Since the centre of gravity is located behind the hook in flight direction also acceleration can affect the pitch angle. Figure 7 shows these effects. In situations with constant TAS the extension of the towing cable points through hook and centre of gravity, while for acceleration or deceleration pitch angle has to be varied to keep them in line. Thus, the pitch angle is positive during acceleration (nose points down) and negative during deceleration (nose points up), respectively.

\subsubsection{Change of altitude}

Climbing or diving of the aircraft have the same effect on AIRTOSS as acceleration or deceleration. In Fig. 4 these periods are denoted by the coarse shaded areas. Altitude change is calculated in metre per second. Climbing causes a positive, diving a negative pitch angle. The correlation of pitch angle and altitude change is displayed in Fig. 8. The left part shows the correlation for AIRTOSS pitch angle and altitude change measured on the Learjet, the right part for altitude change measured on AIRTOSS. The latter shows an almost perfect correlation (correlation coefficient of 0.99 ) while the correlation for pitch angle and Learjet altitude change is 0.83 . The differences in these correlations result from simultaneous speed changes during climb and dive periods. Learjet speed changes will affect Learjet/AIRTOSS geometry; the lower the Learjet speed the larger the altitude difference between Learjet and AIRTOSS. This relation blurs the pitch angle/Learjet altitude change correlation, while AIRTOSS also

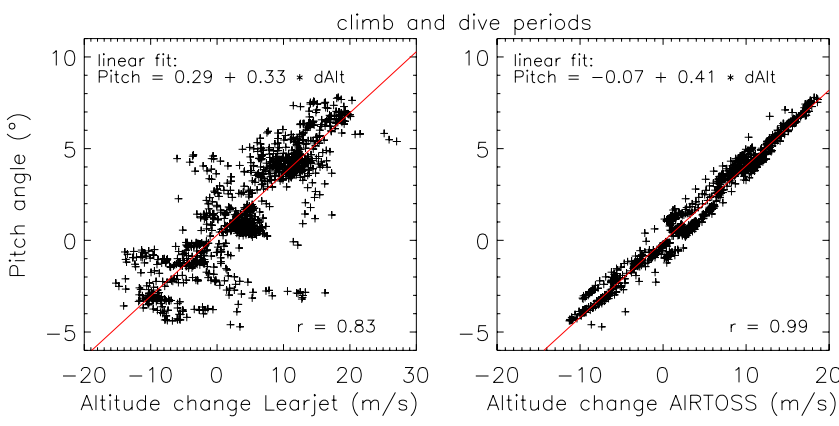

Fig. 8. Correlation between pitch angle and altitude change measured on Learjet (left) and AIRTOSS (right) during climb and dive periods on 6 September 2007.

recognises the altitude change resulting from higher Learjet TAS and thus a better correlation is achieved between pitch angle and AIRTOSS altitude change. The pitch angle variation is explained with a changed air resistance during climb or dive events. While at level flight the force of air resistance is facing towards AIRTOSS, an additional component from the upside or underside of AIRTOSS is added during climb or dive forcing the pitch to increase or decrease, respectively. The Learjet altitude change is easier to observe during flight than AIRTOSS altitude change but might be overlaid with other factors. As is the case during the two dive periods here which are overlaid with a slight acceleration and high TAS. Thus, additional pitch angle components are added: a positive component for acceleration and a negative component for high TAS, refer to Sect. 4.1.2 and 4.1.5. Actually, the regression in Fig. 8 was expected to point through origin but this might be shifted to negative pitch angle values due to these additional pitch angle components. This effect is almost invisible in the AIRTOSS altitude change/pitch angle correlation.

\subsubsection{Change of towing cable length}

Narrow shaded areas in Fig. 4 present situations when the towing cable is extended or retracted. The extension can be seen as deceleration (forcing negative pitch), retraction of towing cable as acceleration (forcing positive pitch). In a retraction case the AIRTOSS speed is the combined airspeed of the Learjet together with the speed of retraction. At the same time AIRTOSS is climbing (coming closer to the Learjet) which shows the same behaviour as acceleration. Thus, the pitch angle increases when towing cable is retracted. In both cases shown here the change in towing cable length concurs to climbing of the aircraft which would cause a positive pitch angle. While the cable is extended a decrease in pitch angle from maximum $7.8^{\circ}$ (caused by climb and concurrent slight acceleration) to less than $1^{\circ}$ is observed, the simultaneous retracting of the cable and climbing causes a strong increase of the pitch angle (maximum 


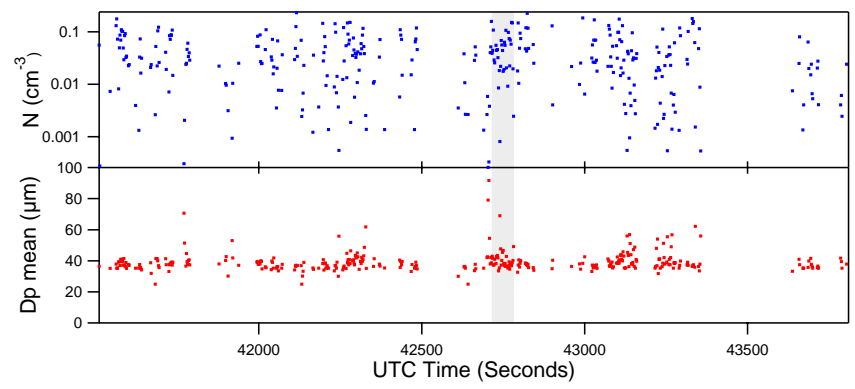

Fig. 9. Averaged (2s) geometric mean diameter (Dp) and number concentration (N) on 7 September 2007. Times used to display the radiation data in Fig. 10 are indicated here in the shaded area (42 710-42 782 s UTC).

$\left.7.5^{\circ}\right)$. The climb rate in this case is not as high as during the towing cable extension case, and thus has a smaller effect.

\subsection{Microphysical and radiation measurements}

This subsection shows examples of analysed cloud microphysical and radiation data to provide evidence of the ability of the tandem measurement platform to obtain simultaneous observations. During 6 cloud legs on 7 September 2007 the AIRTOSS has been released into low marine stratocumulus clouds. The cloud layer was approximately $150 \mathrm{~m}$ thick in an altitude of about $500 \mathrm{~m}$. A radiosonde sounding from the nearby radiosonde station Schleswig at 12:00 UTC is displayed besides a picture taken from the Learjet during the cloud legs in Fig. 6. The photograph and the spread of the sounding show that just a thin layer with high humidity (cloud layer) was present in an altitude of about $1000 \mathrm{~m}$ over land.

The microphysical measurements were made with the CIP. The geometric mean diameter of the cloud droplets and their number concentration averaged over two seconds are displayed in Fig. 9. A detailed description of analysis methods for CIP data is given in de Reus et al. (2008). Predominantly small droplets with a mean maximum diameter of $39 \mu \mathrm{m}$ were detected by the CIP and a mean number concentration of $13 \times 10^{-3}$ particles per $\mathrm{cm}^{3}$ was observed. These values differ from literature values where mean particle diameters of 10-20 $\mu \mathrm{m}$ and number concentrations of some tens of particles per $\mathrm{cm}^{3}$ are given, for example in Miles et al. (2000). The CIP observes particles larger than $25 \mu \mathrm{m}$, and therefore significant numbers of small droplets are not counted. Here, the data are presented for the purpose of demonstrating the general applicability of such probes on AIRTOSS. For future campaigns it is planned to replace the CIP by a Cloud Combination Probe (CCP) which includes a CIP with a resolution of $15 \mu \mathrm{m}$ and a Cloud Droplet Probe (CDP). The operation principle of the CDP is the same as for a FSSP and it measures particles in a size range of $2-50 \mu \mathrm{m}$. Thus, also smaller

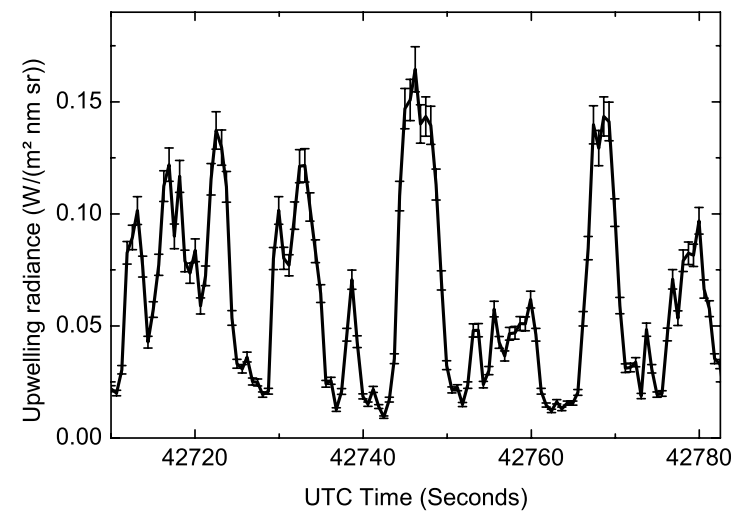

(a) Time series of upwelling radiance at $550 \mathrm{~nm}$ with error bars representing measurement uncertainties.

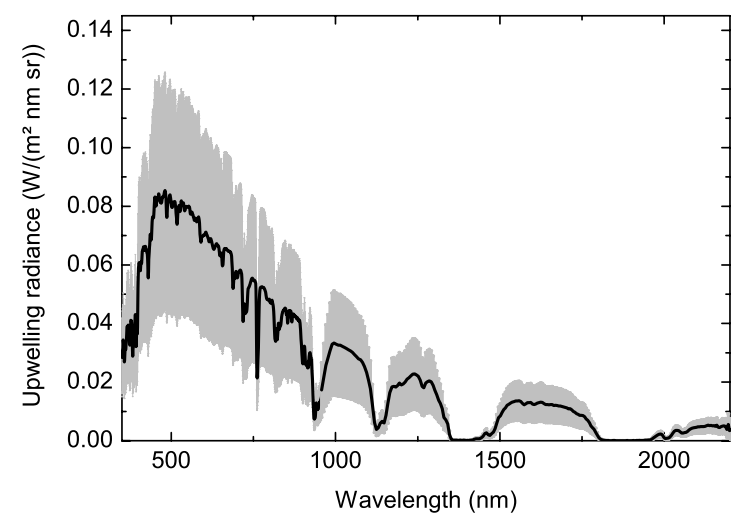

(b) Mean upwelling radiance above inhomogeneous stratocumulus along with its standard deviations in the shaded areas.

Fig. 10. Radiation measurements on 7 September 2007, 42 71042782 s UTC.

particles will be observed. Single particle information will be available. The probe tips are modified to minimise shattering effects. The measurements here show that the AIRTOSS is capable of staying a long duration (about $45 \mathrm{~min}$ in this case) inside clouds and measure its microphysical properties.

Simultaneous to the cloud microphysical measurements also measurements of the upwelling radiances have been made from the Learjet. Examples for time series and mean upwelling radiance spectra above the inhomogeneous stratocumulus on 7 September 2007 are shown in Fig. 10 for a $72 \mathrm{~s}$ period (grey shaded time period in Fig. 9). In the time series of upwelling radiance at $550 \mathrm{~nm}$ wavelength cloud inhomogeneities are obvious. At this wavelength variations over a factor of 7 between $0.025-0.17 \mathrm{~W} \mathrm{~m}^{-2} \mathrm{~nm}^{-1} \mathrm{sr}^{-1}$ were observed, corresponding to roughly $7 \mathrm{~km}$ flight path. The average upwelling radiance spectrum (Fig. 10b), along with standard deviation in the shaded area, in the wavelength range 
400-2200 nm shows that the stratocumulus was rather optically thin since the water vapour absorption bands (e.g. $1120-1130 \mathrm{~nm}, 1400-1500 \mathrm{~nm}, 1800-2000 \mathrm{~nm}$ ) are very pronounced.

\section{Conclusions}

A novel airborne tandem measurement configuration has been developed which allows truly collocated airborne atmospheric measurements at two different altitudes. It consists of a combination of a Learjet which tows a drag-body (AIRTOSS) with an adjustable cable length from 0 to $4 \mathrm{~km}$. Three successful flights with this tandem setup were performed during a proof-of-concept campaign. Several specific manoeuvres at different altitudes, airspeeds, and towing cable lengths were performed and the attitude of the dragbody was measured. During these manoeuvres AIRTOSS was able to stabilise its flight in such a way that it was stable enough to allow radiation and cloud microphysics measurements within the limits imposed by the instruments. The Learjet/AIRTOSS tandem was capable of staying in cloud for a longer time span and therewith capable of performing simultaneous measurements of cloud microphysics and cloud radiation.

Measurements of AIRTOSS flight attitudes showed that the drag-body is sensitive to changes of several Learjet flight parameters. These parameters are altitude, true airspeed, towing cable length (all effecting AIRTOSS pitch angle), and heading (effecting AIRTOSS heading and roll angle). Maximum values of roll angle were found when flying turns. These amount to $\pm 46^{\circ}$, while the mean value for roll angle during turns is about $\pm 15^{\circ}$. Thus, when flying turns, which is inevitable in small restricted areas, a decay time for oscillations in roll angle has to be considered. Since AIRTOSS attitude changes are delayed to Learjet attitude changes depending on towing cable length, the decay time which includes this delay increases with increasing towing cable length. For a $150 \mathrm{~m}$ long towing cable the decay time is in the range of $40 \mathrm{~s}$, including a delay of $14 \mathrm{~s}$. In case of a $4000 \mathrm{~m}$ long towing cable the delay is $35 \mathrm{~s}$. Also stronger centrifugal forces lead to pitch angle variations in cases of long towing cable. Pitch angle variations within a range of $-5^{\circ}$ to $8^{\circ}$ were observed. While the most negative values were found for dive periods or times with TAS change, the highest values were observed during climbs or retraction of towing cable (which happened simultaneously to a slight climb). Since changes in heading or TAS affect roll and pitch angle these changes shall be avoided as good as possible or at least they should be kept in a range of about $\pm 0.35^{\circ} \mathrm{s}^{-1}$ for heading change and $\pm 1.95 \mathrm{~m} \mathrm{~s}^{-2}$ for acceleration of the Learjet. This will keep roll and pitch angle in the tolerable range of $\pm 3^{\circ}$. This value has been chosen from calculations of percental deviations of irradiances due to horizontal misalignment of radiation sensor heads in order to keep these errors small. A summary of minimum and maximum values of flight parameters during the different flight phases is given in Table 5. Turbulences at flight level are possibly leading to higher fluctuations in AIRTOSS roll and pitch angle as standard deviations calculated for roll and pitch angle during constant conditions flight phase indicate. Thus, they should be avoided. Learjet pitch variations are not effecting AIRTOSS attitude.

As a further development of the AIRTOSS, radiation measurements will be implemented onto it. Since a preferable stable flight of AIRTOSS is crucial for quality of radiation measurements, the above mentioned flight parameters (heading, TAS, altitude, and towing cable length) shall be kept constant or need to be measured fast and precisely enough in order to identify and remove periods of poor measurements from the data record. Thus, straight on flight at constant speed shall be preferred and turbulences shall be avoided. Since attitude changes of AIRTOSS are delayed with respect to those of the Learjet in dependency of towing cable length, the towing cable should be kept rather short to avoid a longer time waiting for stable conditions. Also centrifugal forces (especially in turns) are minimised by keeping the towing cable short. With consideration of these recommendations the horizontal misalignment of the radiation sensors will be minimised and thus will be the resulting errors on irradiance measurements. With the implementation of radiation sensors the AIRTOSS/Learjet tandem can be used in more configurations, combining cloud microphysical measurements with radiation measurements of downwelling irradiances measured below cloud and upwelling radiances as well as upwelling and downwelling irradiances above cloud. Also careful manoeuvring and data filtering based on measurements of the attitude sensors allow the recording of several consecutive vertical profiles from cloud layers.

Acknowledgements. We thank enviscope GmbH (http: //www.enviscope.de) for the technical modification of the AIRTOSS and the staff of enviscope and Gesellschaft für Flugzieldarstellung (GFD) for their help during the campaign.

The AIRTOSS has been developed within the Collaborative Research Center The Tropospheric Ice Phase (SFB641) - project B5, funded by the Deutsche Forschungsgemeinschaft (DFG).

Stipend funding by the Research Centre for Earth System Sciences (Geocycles) is acknowledged.

Edited by: P. Laj

\section{References}

Baumgardner, D., Jonsson, H., Dawson, W., O'Connor, D., and Newton, R.: The cloud, aerosol and precipitation spectrometer: a new instrument for cloud investigations, Atmos. Res., 59, 251264, 2001.

de Reus, M., Borrmann, S., Bansemer, A., Heymsfield, A. J., Weigel, R., Schiller, C., Mitev, V., Frey, W., Kunkel, D., Kürten, A., Curtius, J., Sitnikov, N. M., Ulanovsky, A., and Ravegnani, 
F.: Evidence for ice particles in the tropical stratosphere from in-situ measurements, Atmos. Chem. Phys. Discuss., 8, 1931319355, 2008,

http://www.atmos-chem-phys-discuss.net/8/19313/2008/.

DuncanTech: MS4000 and MS4100 High-Resolution Digital Color and Multispectral Camera, DuncanTech, 11824 Kemper Rd. Auburn, CA 95603, USA, 2002.

Dye, J. E. and Baumgardner, D.: Evaluation of the Forward Scattering Spectrometer Probe. Part I: Electronic and Optical Studies, J. Atmos. Ocean. Tech., 1, 329-344, 1984.

Giannakaki, E., Balis, D. S., Amiridis, V., and Kazadzis, S.: Optical and geometrical characteristics of cirrus clouds over a Southern European lidar station, Atmos. Chem. Phys., 7, 5519-5530, 2007, http://www.atmos-chem-phys.net/7/5519/2007/.

Jensen, E., Starr, J., D., and Toon, O. B.: Mission Investigates Tropical Cirrus Clouds, Eos Trans. AGU, 85, 45-50, 2004.

Lynch, D. K.: Cirrus, Oxford University Press, Cambridge, New York, USA, 2002.
Miles, N. L., Verlinde, J., and Clothiaux, E. E.: Cloud Droplet Size Distributions in Low-Level Stratiform Clouds, J. Atmos. Sci., 57, 295-311, 2000.

Solomon, S., Qin, D., Manning, M., Chen, Z., Marquis, M., Averyt, K. B., Tignor, M., and Miller, H. L. (Eds.): Climate Change 2007: The Physical Science Basis. Contribution of Working Group I to the Fourth Assessment Report of the Intergovernmental Panel on Climate Change, Cambridge University Press, Cambridge University Press, Cambridge, UK and New York, USA, 2007.

Toon, O. B.: An Overview of the Tropical Composition, Clouds and Climate Coupling Experiment, AGU Fall Meeting Abstracts, 88, Abstract21F-01, 2007.

University of Wyoming: Atmospheric Soundings, http://weather. uwyo.edu/upperair/europe.html, access 27 November 2008.

Wendisch, M., Müller, D., Schell, D., and Heintzenberg, J.: An airborne spectral albedometer with active horizontal stabilization, J. Atmos. Ocean. Tech., 18, 1856-1866, 2001. 